\title{
Conversion of imidazoles to imidazolones with chloramine-B: kinetic and mechanistic study
}

\author{
A. S. Manjunatha ${ }^{1} \cdot$ Puttaswamy $^{1}$
}

Received: 24 July 2015/ Accepted: 10 January 2016

(C) Springer-Verlag Wien 2016

\begin{abstract}
Oxidative conversion of $1 H$-imidazole (IzlH) and 2-substituted imidazoles viz., 2-ethyl- $1 \mathrm{H}$-imidazole (2EtIzlH), 2-methyl-1H-imidazole (2-MeIzlH), $1 H$-imidazole-2-ester (2-EsIzlH), and $1 \mathrm{H}$-imidazole-2-carbaldehyde (2-CaIzlH) to the corresponding imidazolones with sodium $\mathrm{N}$-chlorobenzenesulfonamide or chloramine-B (CAB) were established. This reaction was kinetically investigated at $303 \mathrm{~K}$ in $\mathrm{HClO}_{4}$ medium. Under comparable experimental conditions, the oxidation reactions followed identical kinetics for all the five imidazoles with a first-order dependence of rate on $[\mathrm{CAB}]_{\mathrm{o}}$ and fractional-order dependence each on [imidazole $]_{\mathrm{o}}$ and $\left[\mathrm{H}^{+}\right]$. Effects of added benzenesulfonamide, halide ions, $\mathrm{NaClO}_{4}$, and $\mathrm{MeOH}$ on the rate of reaction have been studied. Reaction products were identified and characterized by GC-MS and NMR spectral analysis. The rates are measured at different temperatures and the composite activation parameters have been computed from the Arrhenius plots. Isokinetic temperature $(\beta)$ was found to be $449 \mathrm{~K}$ which is higher than the experimental temperature $(303 \mathrm{~K})$, indicating that the rate has been under enthalpy control. Relative reactivity of these imidazoles is in the order: 2-EtIzlH $>2$-MeI$\mathrm{zlH}>\mathrm{IzlH}>2$-EsIzlH $>2$-CaIzlH. $\mathrm{H}_{2} \mathrm{O}^{+} \mathrm{Cl}$ have been postulated as the reactive oxidizing species. The reaction mechanism and the derived rate law are in good agreement with the observed experimental results. Spectroscopic
\end{abstract}

Electronic supplementary material The online version of this article (doi:10.1007/s00706-016-1663-4) contains supplementary material, which is available to authorized users.

\footnotetext{
Puttaswamy

pswamy_chem@yahoo.com

1 Department of Chemistry, Bangalore University, Central College Campus, Bangalore 560 001, India
}

studies have been made for an intermediate complex formation between $\mathrm{CAB}$ and imidazole. Advantages of the present method include: mild reaction conditions, cost-effectiveness, short reaction time, ease of isolation of products, and the use of eco-friendly reagents. Hence, the methodology developed could be adopted for the facile oxidative conversion of imidazoles to imidazolones and can be scaled up to industrial operation with suitable modification.

Graphical abstract

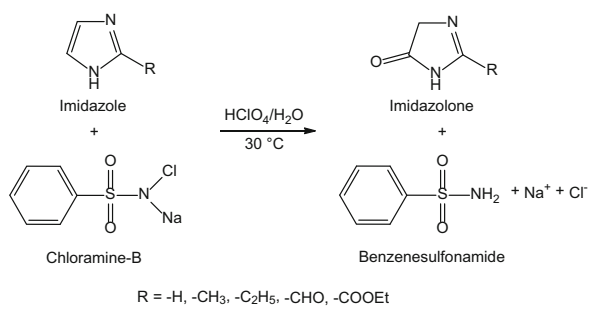

Keywords Imidazole $\cdot$ Chloramine-B .

Oxidation kinetics - Mechanism - Activation parameters . Structure reactivity

\section{Introduction}

Oxidation of organic compounds with high selectivity is a foremost transformation in organic synthesis and important in mechanistic chemistry. Chemical kinetics deals with the study of the rates of chemical reactions and with the description of the mechanism by which they proceed. Hence, oxidation-kinetic study is the significant area of research in chemistry to suit the optimum conditions and to unfold the 
mechanistic chemistry of a particular reaction $[1,2]$. Imidazole is a five-membered planar ring and it exists in two equivalent tautomeric forms. Imidazoles show amphoteric properties. Imidazole is incorporated into many important biological molecules and the most pervasive is histidine. Imidazoles are common components of a large number of natural products and pharmaceutically active molecules. Imidazole and its derivatives possess a number of versatile properties and pharmaceutical applications include anticancer, antiinflammatory, antibacterial, antifungal, antiviral, antitubercular, antidiabetic, and antimalarial ones [3]. Substituted imidazoles are important moieties constituted in pharmaceuticals, pesticides, and bioactive compounds [4]. Many imidazoles with a single heterocyclic substituent in the 2-position serve as key intermediates in the synthesis of pharmaceutically active compounds. Mild oxidation of imidazoles to imidazolones find importance in synthetic organic chemistry and considerable work has been carried out in this direction [5]. Further, various kinds of imidazolones are biologically and pharmaceutically very important, since many of them possess antihypertensive, antidiabetic, and antiinflammatory force [6]. In spite of extensive medicinal applications of imidazoles and imidazolones, no information is available on the oxidative conversion of imidazoles to imidazolones from the kinetic and mechanistic point of view. Therefore, the mechanistic picture and rate law for these redox systems were obscure. Hence, it is very essential to know the kinetic and mechanistic basis for the redox chemistry of these systems. This kind of research knowledge would be very beneficial to synthetic chemists and also kineticists who are working on the mechanistic chemistry of imidazoles in biological systems. For these reasons, in the present research, conversion of imidazoles and 2-imidazoles to the corresponding imidazolones have been developed for our oxidation-kinetic and mechanistic study.

Organic sulfonyl- $N$-haloamines ( $N$-haloamines) are mild oxidizing/halogenating/analytical reagents containing a strongly polarized $\mathrm{N}$-bonded halogen in its +1 oxidation state [7]. Kinetics and mechanism of oxidation by these reagents have attracted the attention of chemists due to their diverse properties to act as halonium cations, hypohalites and $\mathrm{N}$-anions [7]. They interact with a wide range of functional groups in aqueous, partially aqueous and nonaqueous media in the presence of an acid or a base. As a result, these reagents have been used as mild and selective oxidizing agents in synthetic organic and mechanistic chemistry [7-12]. The prominent member of this group of compounds is sodium- $N$-chloro- $p$-toluenesulfonamide, commonly known as chloramine-T (CAT), it is a wellknown oxidizing/halogenating/analytical agent and the kinetic and mechanistic aspects of many of its reactions have been well documented [7-13]. Sodium- $N$ - chlorobenzenesulfonamide or chloramine- $\mathrm{B}(\mathrm{CAB})$ is the benzene analogue of CAT, which can be easily prepared from the reaction of benzenesulfonamide and chlorine in basic solutions. Chloramine-B is a stable compound with slightly higher active chlorine content than CAT. There are but few reports on the synthetic and mechanistic chemistry of $\mathrm{CAB}[8,12,14-16]$.

Our initial experiments began with the examination of oxidation of the selected imidazoles with CAT in acid medium. These redox systems at different experimental conditions were too sluggish to be measured kinetically. Then we thought of using $\mathrm{CAB}$ as an oxidant and we were delighted to see that the reactions proceeded smoothly. Hence, $\mathrm{CAB}$ is an excellent oxidant in effectively controlled conversion of 2-imidazoles to corresponding imidazolones. Consequently, in the course of this research, optimum conditions for the facile oxidation of 2-imidazoles to 2-imidazolones with $\mathrm{CAB}$ in acid medium were established. The present paper reports the oxidation-kinetics of the imidazoles and substituted imidazoles viz., 2-ethyl-1 $H$-imidazole (2-EtIzlH), 2-methyl-1H-imidazole (2-MeIzlH), $1 H$-imidazole(IzlH), $1 H$-imidazole-2-ester (2EsIzlH), and $1 H$-imidazole-2-carbaldehyde (2-CaIzlH) with $\mathrm{CAB}$ in acid medium at $303 \mathrm{~K}$. Additionally, these synthesized imidazolones are useful as intermediates for polymers, agrochemicals, and pharmaceutical compounds. Objectives of the present research are to: (a) establish optimum conditions for the facile oxidation of 2-imidazoles to 2-imidazolones; (b) deduce all the possible kinetic data; (c) elucidate the possible reaction mechanism (scheme); (d) put forward kinetic rate law; (e) identify the stoichiometry and oxidation products; (f) ascertain the reactive species; $(\mathrm{g})$ establish the isokinetic relationship through activation parameters; and (h) asses the relative reactivity of imidazoles.

\section{Results and discussion}

\section{Reaction stoichiometry}

Varying ratios of $\mathrm{CAB}$ to imidazoles in the presence of $5.0 \times 10^{-4} \mathrm{~mol} \mathrm{dm}^{-3} \mathrm{HClO}_{4}$ were equilibrated at $303 \mathrm{~K}$ for $48 \mathrm{~h}$. Determination of the unreacted $\mathrm{CAB}$ showed that one mole of the imidazole consumed one mole of $\mathrm{CAB}$ in all the cases. Accordingly, the stoichiometric Eq. (1) can be formulated (Scheme 1).

\section{Representative oxidation procedure for the conversion of imidazoles to imidazolones}

A mixture of $0.68 \mathrm{~g}$ of imidazole, $2.13 \mathrm{~g}$ of oxidant (chloramine-B) in presence of $2.5 \mathrm{~cm}^{3}\left(0.01 \mathrm{~mol} \mathrm{dm}^{-3}\right)$ of 


\section{Scheme 1}

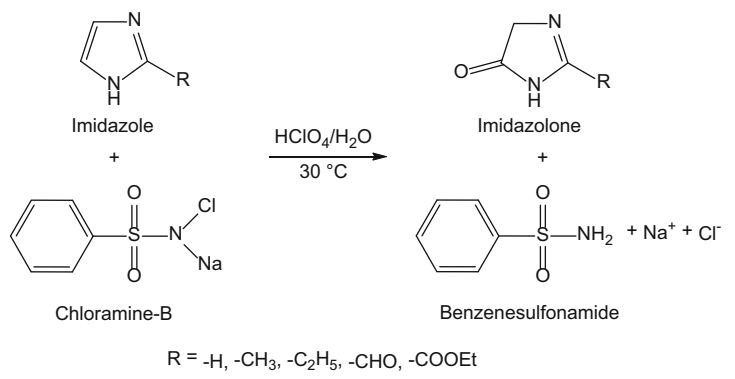

aqueous perchloric acid was stirred at $303 \mathrm{~K}$ for $8-10 \mathrm{~h}$. After completion of the reaction (monitored by TLC), the reaction products were neutralized with alkali and extracted with ether. The organic products were subjected to spot tests and chromatographic analysis (TLC technique). Further, the reaction mixture was extracted with ethyl acetate and dried over sodium sulfate. The solvent was evaporated under reduced pressure to obtain crude products. The crude products were purified on silica gel column by using petroleum ether and ethyl acetate as solvents to get the pure products. Above analyses revealed the formation of corresponding imidazolones as the oxidation products of imidazoles. 3,5-Dihydroimidazol-4-one, 2-methyl-3,5-dihydroimidazol-4-one, 2-ethyl-3,5-dihydroimidazol-4-one, 3,5-dihydro-4-oxoimidazol-2-carbaldehyde, and 3,5-dihydro-4-oxoimidazol-2-ester are the oxidation products of $1 H$-imidazole, 2-methyl- $1 H$-imidazole, 2-ethyl- $1 H$-imidazole, $1 H$-imidazole-2-carbaldehyde, and $1 H$-imidazole-2ester, respectively. The mass spectra showed a molecular ion peak at $m / z=84$ amu (Fig. 1), 99 amu $(\mathrm{M}+1$, Fig. 2), and 112 amu (Fig. 3), clearly confirming 3,5-dihydroimidazol-4-one, 2-methyl-3,5-dihydroimidazol-4one, and 2-ethyl-3,5-dihydroimidazol-4-one as oxidation products of $1 H$-imidazole, 2-methyl- $1 H$-imidazole, and 2-ethyl-1H-imidazole, respectively. Further these products were confirmed by NMR data (supplementary material, Figs. 1s-3s). Furthermore, we have succeeded in estimating the products, imidazolones, in case of all the five imidazoles. In some typical experiments, the weight of imidazolones and their percentage yield obtained are recorded in Table 1 . The recovery of imidazolones was 87-93\% yields. Further no reaction was noticed between oxidation products and $\mathrm{CAB}$ under prevailing experimental conditions.

\section{Kinetic orders}

The kinetics of oxidation of imidazole and 2-substituted imidazoles (henceforth abbreviated as imidazole) by CAB was investigated at several initial concentrations of the reactants in the presence of $\mathrm{HClO}_{4}$ at $303 \mathrm{~K}$. Similar oxidation-kinetic behavior was observed for all five imidazoles studied under identical experimental conditions.

\section{Effect of varying reactant concentrations on the reaction rate}

The reactions performed in the presence of $\mathrm{HClO}_{4}$, under pseudo-first-order conditions of [imidazole $]_{\mathrm{o}} \gg[\mathrm{CAB}]_{\mathrm{o}}$, gave linear plots of $\log [\mathrm{CAB}]$ vs. time $\left(R^{2}>0.9884\right)$. The linearity of these plots, together with the constancy of the slopes for various $[\mathrm{CAB}]_{\mathrm{o}}$, indicating a first-order dependence of the rate on $[\mathrm{CAB}]_{\mathrm{o}}$. The pseudo-first-order rate constants $\left(k^{\prime} / \mathrm{s}^{-1}\right)$ obtained are listed in Table 2 . Under the same experimental conditions, an increase in [imidazole] increased the $k^{\prime}$ values (Table 2). Plots of $\log k^{\prime}$ vs. $\log$ [imidazole] were linear $\left(R^{2}>0.9900\right)$ with fractional slopes (0.27-0.51), showing a fractional-order dependence of the rate on [imidazole] . Further, plots of $k^{\prime}$ vs. [imidazole] were linear $\left(R^{2}>0.9900\right)$ with a y-intercept, confirming a fractional-order dependence of rate on [imidazole $]_{0}$. The rate increased with increase in $\left[\mathrm{HClO}_{4}\right]$ (Table 2) and plots of $\log k^{\prime}$ vs. $\log \left[\mathrm{HClO}_{4}\right]$ were linear $\left(R^{2}>0.9707\right)$ with fractional slopes $(0.26-0.54)$, thus illustrating a fractional-order dependence of rate on $\left[\mathrm{H}^{+}\right]$. Further, plots of $k^{\prime}$ vs. $\left[\mathrm{H}^{+}\right]$were linear $\left(R^{2}>0.9900\right)$ with a $y$-intercept corresponding to a rate law of the type: rate $=a+b\left[\mathrm{H}^{+}\right]$and confirming the order to be less than unity with respect to $\left[\mathrm{H}^{+}\right]$.

\section{Effect of varying benzenesulfonamide (BSA) on the reaction rate}

Addition of benzenesulfonamide (BSA) to the reaction mixture retards the rate (Table 3) while keeping other experimental conditions constant. Plots of $\log k^{\prime}$ vs. $\log$ [BSA] were linear $\left(R^{2}>0.9924\right)$ with negative fractional slopes (0.10-0.42), indicating the involvement of BSA with oxidant in a pre-equilibrium step prior to the ratelimiting step (rls).

\section{Effect of varying ionic strength of the medium on the reaction rate}

The effect of ionic strength of the medium on the reaction rate was carried with $0.2 \mathrm{~mol} \mathrm{dm}{ }^{-3} \mathrm{NaClO}_{4}$ solution by keeping other experimental conditions constant. It was found that ionic strength had negligible effect on the reaction rate indicating that non-ionic species are involved in the rls. Subsequently, the ionic strength of the reaction mixture was not kept constant for kinetic runs. 
Fig. 1 Mass spectrum of 3,5dihydroimidazol-4-one with its parent molecular ion peak at $\mathrm{m} / z=84 \mathrm{amu}$

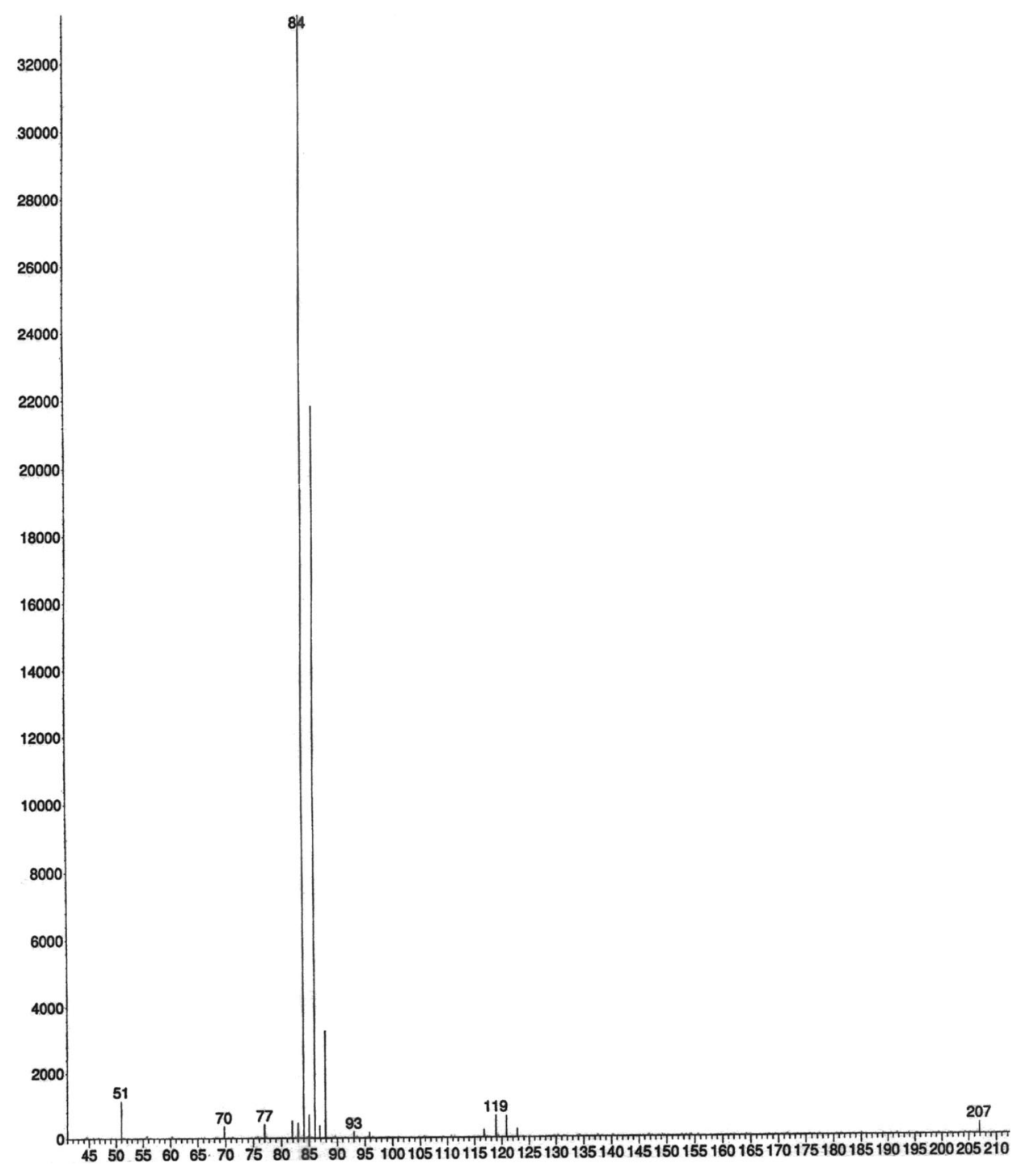

\section{Effect of varying dielectric constant of the medium} on the reaction rate

The dielectric constant $(D)$ of the medium was varied using different proportions of $\mathrm{MeOH}$ and $\mathrm{H}_{2} \mathrm{O}(0-15 \%, \mathrm{v} / \mathrm{v})$, keeping other experimental conditions constant. The reaction rate increased with increase in methanol content (Table 4) and plots of $\log k^{\prime}$ vs. $1 / D$ were found to be linear $\left(R^{2}>0.9933\right)$ with positive slopes. Values of dielectric constant of $\mathrm{MeOH}$ $\mathrm{H}_{2} \mathrm{O}$ reported in the literature [17] were employed. Blank experiments performed showed that $\mathrm{MeOH}$ was not oxidized by $\mathrm{CAB}$ under the prevailing experimental conditions.

\section{Effect of varying temperature on the reaction rate}

To calculate the activation parameter, the reaction was studied over a range of temperatures (288-323 K), keeping other experimental conditions constant. From the linear
Arrhenius plots of $\log k^{\prime}$ vs. $1 / T\left(R^{2}>0.9988\right)$, values of activation parameters $\left(E_{\mathrm{a}}, \Delta H^{\neq}, \Delta S^{\neq}, \Delta G^{\neq}\right.$, and $\left.\log A\right)$ for the composite reactions were calculated. These data are tabulated in Table 5.

\section{Effect of $\mathrm{Cl}^{-}$ion on the reaction rate}

The effect of $\mathrm{Cl}^{-}$ion on the rate of the reaction was studied using $0.2 \mathrm{M} \mathrm{NaCl}$. There was no significant effect of $\mathrm{Cl}^{-}$ on the rate, suggesting no interhalogen or free chlorine was formed during the reaction sequence.

\section{Polymerization study}

Addition of acrylamide solution to the reaction mixture did not initiate polymerization, showing the absence of free radical species. This clearly ruled out the possibility of free radical mechanism. 
Fig. 2 Mass spectrum of 2-methyl-3,5-dihydroimidazol4-one with its parent molecular ion peak at $m / z=99 \mathrm{amu}$ $(\mathrm{M}+1)$

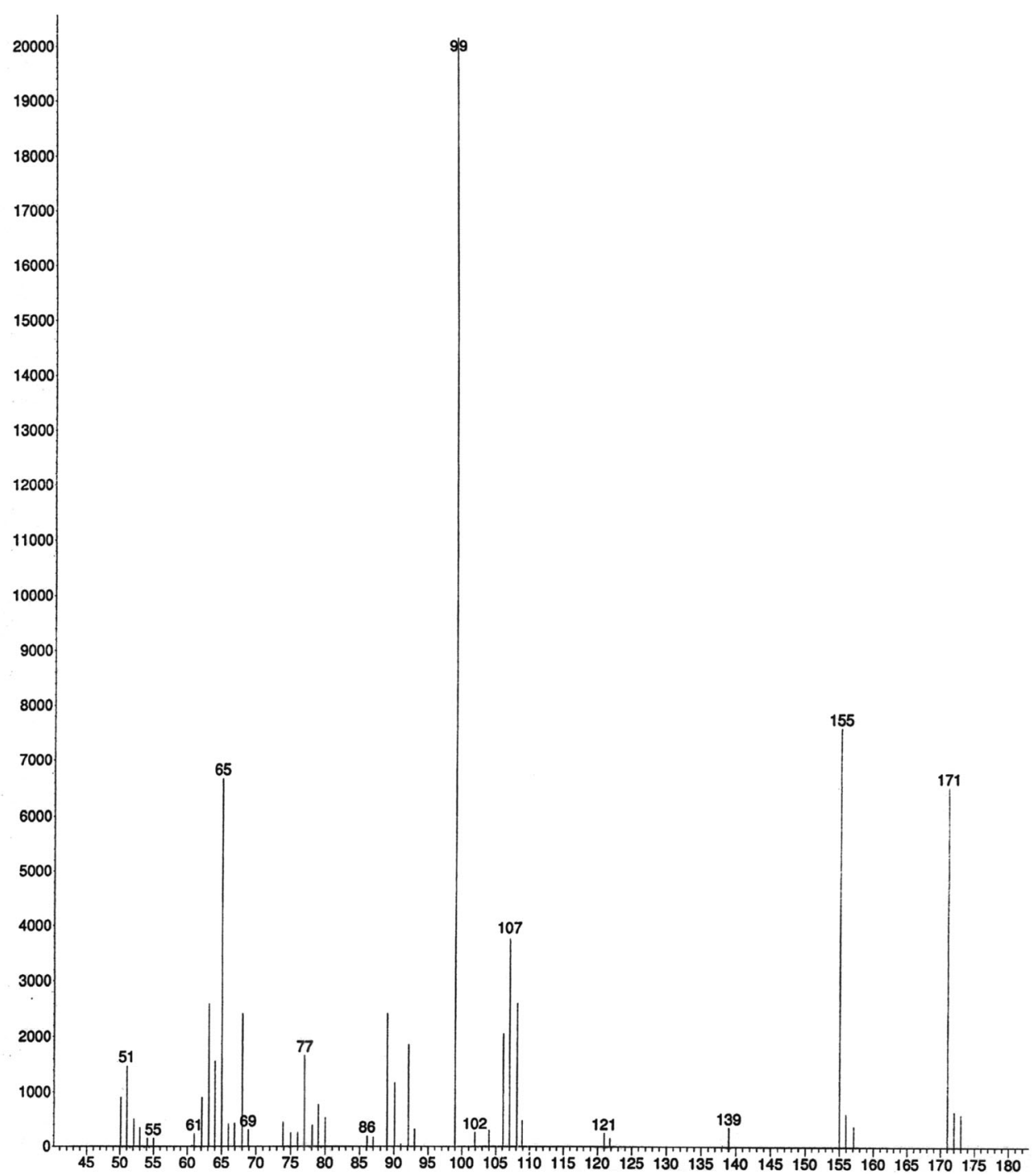

\section{Oxidizing species of CAB}

Chloramine- $\mathrm{B},\left(\mathrm{PhSO}_{2} \mathrm{NClNa}\right)$ like chloramine- $\mathrm{T}$, is a mild and effective oxidizing agent in both acidic and alkaline media due to its versatile behavior [7]. In general, $\mathrm{CAB}$ undergoes a two electron change in its reactions forming the reduction products $\mathrm{BSA}$ and $\mathrm{NaCl}$ [18]. The redox potential of $\mathrm{CAB} / \mathrm{BSA}$ is $\mathrm{pH}$ dependent and decreases with increases in $\mathrm{pH}$ of the medium.

Chloramine-B behaves as a strong electrolyte [19] in aqueous solutions and depending upon the $\mathrm{pH}$ of the medium it furnishes following types of reactive species in solutions [19-21] (Scheme 2).

Chloramine-B dissociates to give an anion $\mathrm{PhSO}_{2} \mathrm{NCl}^{-}$ as shown in reaction (2). The anion picks up a proton in acid medium to give the free acid $\mathrm{PhSO}_{2} \mathrm{NHCl}$ according to reaction (3). This free acid undergoes disproportionation [20] via reaction (4) giving rise to dichloramine-B and the parent amide. Dichloramine-T and the free acid undergo hydrolysis according to reactions (5) and (6). $\mathrm{PhSO}_{2} \mathrm{NHCl}$ further protonates to give diprotonated species as shown in reaction (7). This diprotonated species hydrolyzed to yield $\mathrm{PhSO}_{2} \mathrm{NH}_{2}$ and $\mathrm{H}_{2} \mathrm{O}^{+} \mathrm{Cl}$ species, reaction (8). Finally hypochlorous acid ionizes according to reaction (9). Therefore, the possible oxidizing species in acidified $\mathrm{CAB}$ solutions are $\mathrm{PhSO}_{2} \mathrm{NHCl}, \mathrm{PhSO}_{2} \mathrm{NCl}_{2}, \mathrm{HOCl}$, and $\mathrm{H}_{2} \mathrm{O}^{+} \mathrm{Cl}$.

If $\mathrm{PhSO}_{2} \mathrm{NCl}_{2}$ were to be the reactive species, then the rate law predicts a second-order dependence of rate on $[\mathrm{CAB}]_{\mathrm{o}}$, see Eq. (4) but experimentally clear first-order plots were obtained for the disappearance of CAB. Soper [22] reported that $[\mathrm{HOCl}]$ is very small in acidified $\mathrm{CAB}$ solution and is independent of the $[\mathrm{CAB}]$. On the basis of the above facts, the role of $\mathrm{PhSO}_{2} \mathrm{NCl}_{2}$ and $\mathrm{HOCl}$ in the present case can be ignored. Further, Swain and Crist [23] have pointed out in their studies that hypochlorite ion 
Fig. 3 Mass spectrum of 2-ethyl-3,5-dihydroimidazol-4one with its parent molecular ion peak at $\mathrm{m} / \mathrm{z}=112 \mathrm{amu}$

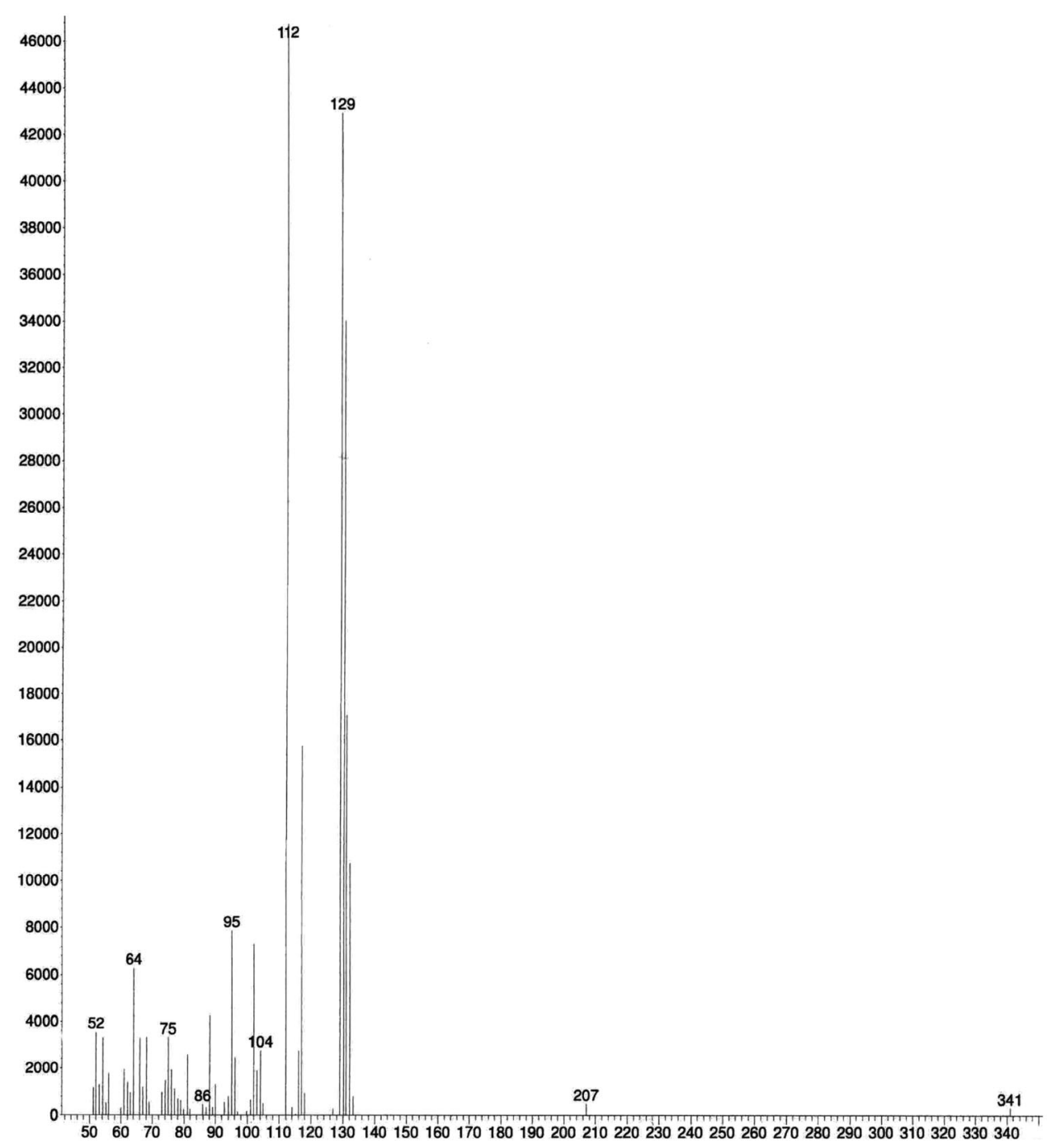

formed in a prior equilibrium before the rate-limiting step is a better electrophile than $\mathrm{HOCl}$. Formation of the species of the type $\mathrm{PhSO}_{2} \mathrm{~N}^{+} \mathrm{H}_{2} \mathrm{Cl}$ has been reported with $\mathrm{CAB}$ in acid medium (Eq. (7)). In the present investigations, the rate of the reaction increases with increase in $\left[\mathrm{H}^{+}\right]$but it is retarded by the added $\mathrm{BSA}\left(\mathrm{PhSO}_{2} \mathrm{NH}_{2}\right)$. This indicates that Eqs. (7) and (8) play a dominant role in the present case. Furthermore, $\mathrm{CAB}$ contains a polar $\mathrm{N}-\mathrm{Cl}$ bond as the source of positive chlorine $\mathrm{Cl}^{+}$species, which forms the conjugate acid, $\mathrm{PhSO}_{2} \mathrm{NHCl}$ in acidic solutions. The conjugate acid with $\mathrm{N}-\mathrm{Cl}$ bond in fact interacts with the hydronium ion $\left(\mathrm{H}_{3} \mathrm{O}^{+}\right)$, to form the reactive oxidant species $\mathrm{H}_{2} \mathrm{O}^{+} \mathrm{Cl}$ and the $\mathrm{BSA}\left(\mathrm{PhSO}_{2} \mathrm{NH}_{2}\right)$ [24]. Hence, the most reactive oxidizing species in the present case is $\mathrm{H}_{2} \mathrm{O}^{+} \mathrm{Cl}$.

Spectroscopic measurements were made for imidazole, $\mathrm{CAB}$, and a mixture of both. Absorption maxima of 214, 220 , and $216 \mathrm{~nm}$ for imidazole, $\mathrm{CAB}$ and a mixture of both were noticed in acidic solutions (Fig. 4). A hypsochromic shift of $4 \mathrm{~nm}$ from 220 to $216 \mathrm{~nm}$ of CAB was observed. This can be probably attributed to complexation between $\mathrm{CAB}$ and imidazole.

In the light of these considerations, a mechanism (Scheme 3) is formulated for the oxidation of imidazole and 2-substituted imidazoles with $\mathrm{CAB}$ in acid medium to substantiate the observed experimental results.

A detailed mechanistic interpretation for the Scheme 3 has been worked out in Scheme 4. In Scheme 4, an initial equilibrium step involves protonation of $\mathrm{CAB}$ forming an active oxidizing species, $\mathrm{H}_{2} \mathrm{O}^{+} \mathrm{Cl}$ with the elimination of $\mathrm{PhSO}_{2} \mathrm{NH}_{2}$ as shown in step (i). In the next pre-equilibrium fast step (ii) an electrophilic attack of the positive chlorine of the oxidizing species $\mathrm{H}_{2} \mathrm{O}^{+} \mathrm{Cl}$ at the 5-position of the imidazole followed by the elimination of a proton and addition of a proton at the 4-position may give chloro substituted intermediate complex. In the next slow and rls step the intermediate complex undergoes a nucleophilic attack at the iminium carbon by $\mathrm{H}_{2} \mathrm{O}$ followed by loss of a 
Table 1 Percentage yield of imidazolones obtained from the oxidation of imidazoles with CAB in acid medium

\begin{tabular}{ccccc}
\hline Imidazoles & $\begin{array}{c}\text { Weight of imidazolone } \\
\text { Ig (found) }\end{array}$ & $\begin{array}{c}\text { Weight of imidazolone } \\
\text { /g (expected) }\end{array}$ & $\begin{array}{c}\text { Yield of } \\
\text { imidazoles } / \%\end{array}$ \\
\hline
\end{tabular}

Experimental conditions: equimolar quantities of $\mathrm{CAB}$ and imidazoles were taken to calculate the percentage yield of imidazolones

molecule of $\mathrm{HCl}$ to give the final product imidazolone as shown in step (iii).

\section{Deduction of rate law}

From the slow and rate-limiting step (iii) of Scheme 3,

Rate $=k_{3}[$ Complex $]$

The value of the complex can be determined as follows: the total concentration of $\mathrm{CAB}$ is given as

$[\mathrm{CAB}] \mathrm{t}=\left[\mathrm{PhSO}_{2} \mathrm{NHCl}\right]+\left[\mathrm{H}_{2} \mathrm{O}^{+} \mathrm{Cl}\right]+[$ Complex $]$

From steps (i) and (ii) of Scheme 3,

$\left[\mathrm{PhSO}_{2} \mathrm{NHCl}\right]=\frac{\left[\mathrm{PhSO}_{2} \mathrm{NH}_{2}\right][\text { Complex }]}{K_{1} K_{2}\left[\mathrm{H}_{3} 0^{+}\right][\text {Imidazole }]}$

$\left[\mathrm{H}_{2} \mathrm{O}^{+} \mathrm{Cl}\right]=\frac{[\text { Complex }]}{\mathrm{K}_{2}[\text { Imidazole }]}$

By substituting for $\left[\mathrm{PhSO}_{2} \mathrm{NHCl}\right]$ and $\left[\mathrm{H}_{2} \mathrm{O}^{+} \mathrm{Cl}\right]$ from Eqs. (12) and (13) into Eq. (11) and solving for [Complex], we get

$$
[\text { Complex }]=\frac{\mathrm{K}_{1} \mathrm{~K}_{2}[\mathrm{CAB}] \mathrm{t}[\text { Imidazole }]\left[\mathrm{H}_{3} \mathrm{O}^{+}\right]}{\left[\mathrm{PhSO}_{2} \mathrm{NH}_{2}\right]+\mathrm{K}_{1}\left[\mathrm{H}_{3} \mathrm{O}^{+}\right]+\mathrm{K}_{1} \mathrm{~K}_{2}[\text { Imidazole }]\left[\mathrm{H}_{3} \mathrm{O}^{+}\right]}
$$

Upon substituting for [Complex] from Eq. (14) into Eq. (10), one obtains

$$
\text { Rate }=\frac{\mathrm{K}_{1} \mathrm{~K}_{2} \mathrm{k}_{3}[\mathrm{CAB}] \mathrm{t}[\text { Imidazole }]\left[\mathrm{H}_{3} \mathrm{O}^{+}\right]}{\left[\mathrm{PhSO}_{2} \mathrm{NH}_{2}\right]+\mathrm{K}_{1}\left[\mathrm{H}_{3} \mathrm{O}^{+}\right]+\mathrm{K}_{1} \mathrm{~K}_{2}[\text { Imidazole }]\left[\mathrm{H}_{3} \mathrm{O}^{+}\right]}
$$

Rate law (15) is in accordance all observed kinetic data, in which a first-order dependence of rate on $[\mathrm{CAB}]_{\mathrm{o}}$, fractional-order dependence each on [imidazole $]_{\mathrm{o}}$ and $\left[\mathrm{H}^{+}\right]$, and an inverse-fractional-order on $\left[\mathrm{PhSO}_{2} \mathrm{NH}_{2}\right]$ was noticed.

\section{Evaluation of reaction constants}

Since rate $=k^{\prime}[\mathrm{CAB}]_{\mathrm{t}}$, under pseudo-first-order conditions of $[\mathrm{CAB}]_{\mathrm{o}} \ll<$ [imidazole $]_{\mathrm{o}}$, Eq. (15) can be transformed as:

$k^{\prime}=\frac{K_{1} K_{2} k_{3}[\text { Imidazole }]\left[\mathrm{H}_{3} \mathrm{O}^{+}\right]}{\left[\mathrm{PhSO}_{2} \mathrm{NH}_{2}\right]+K_{1}\left[\mathrm{H}_{3} \mathrm{O}^{+}\right]+K_{1} K_{2}[\text { Imidazole }]\left[\mathrm{H}_{3} \mathrm{O}^{+}\right]}$

$\frac{1}{k^{\prime}}=\frac{\left[\mathrm{PhSO}_{2} \mathrm{NH}_{2}\right]}{K_{1} K_{2} k_{3}[\text { Imidazole }]\left[\mathrm{H}_{3} \mathrm{O}^{+}\right]}+\frac{1}{\left.K_{2} k_{3} \text { [midazole }\right]}+\frac{1}{k_{3}}$

$\frac{1}{k^{\prime}}=\frac{1}{\text { [Imidazole }]}\left\{\frac{\left[\mathrm{PhSO}_{2} \mathrm{NH}_{2}\right]}{K_{1} K_{2} k_{3}\left[\mathrm{H}_{3} \mathrm{O}^{+}\right]}+\frac{1}{K_{2} k_{3}}\right\}+\frac{1}{k_{3}}$

In order to deduce equilibrium and decomposition constants, according to Eqs. (17) and (18), the reaction was studied at constant $4.0 \times 10^{-4} \mathrm{~mol} \mathrm{dm}^{-3}$ 
Table 2 Effect of varying $\mathrm{CAB}$ and imidazole concentrations of the reaction rate at $303 \mathrm{~K}$

\begin{tabular}{|c|c|c|c|c|c|c|c|c|}
\hline \multirow{2}{*}{$\begin{array}{l}{[\mathrm{CAB}]_{\mathrm{o}} \times} \\
10^{4} / \mathrm{mol} \mathrm{dm}^{-3}\end{array}$} & \multirow{2}{*}{$\begin{array}{l}\text { [imidazole] } \times \\
10^{3} / \mathrm{mol} \mathrm{dm}^{-3}\end{array}$} & \multirow{2}{*}{$\begin{array}{l}{\left[\mathrm{HClO}_{4}\right] \times} \\
10^{4} / \mathrm{mol} \mathrm{dm}^{-3}\end{array}$} & \multirow{2}{*}{$\begin{array}{l}{[\mathrm{BSA}] \times} \\
10^{4} / \mathrm{mol} \mathrm{dm}^{-3}\end{array}$} & \multicolumn{5}{|l|}{$k^{\prime} \times 10^{4} / \mathrm{s}^{-1}$} \\
\hline & & & & 2-EtIzlH & 2-MeIzH & IzlH & 2-EsIzlH & 2-CaIzlH \\
\hline 0.20 & 1.00 & 5.00 & - & 9.15 & 6.35 & 5.32 & 4.93 & 2.63 \\
\hline 0.50 & 1.00 & 5.00 & - & 9.20 & 6.41 & 5.30 & 4.89 & 2.62 \\
\hline 1.00 & 1.00 & 5.00 & - & 9.21 & 6.39 & 5.35 & 4.96 & 2.65 \\
\hline 2.00 & 1.00 & 5.00 & - & 9.25 & 6.41 & 5.29 & 4.94 & 2.71 \\
\hline 4.00 & 1.00 & 5.00 & - & 9.23 & 6.38 & 5.38 & 4.95 & 2.68 \\
\hline 1.00 & 0.10 & 5.00 & 4.0 & $1.96(1.85)$ & $1.60(1.55)$ & $1.45(1.30)$ & $1.32(1.15)$ & $1.20(1.02)$ \\
\hline 1.00 & 0.50 & 5.00 & 4.0 & $5.50(4.70)$ & $4.25(3.74)$ & $3.35(2.84)$ & $3.05(2.31)$ & $2.00(1.47)$ \\
\hline 1.00 & 1.00 & 5.00 & 4.0 & $9.21(7.93)$ & $6.39(4.72)$ & $5.35(3.74)$ & $4.96(2.75)$ & $2.65(1.59)$ \\
\hline 1.00 & 2.00 & 5.00 & 4.0 & $13.4(11.8)$ & $8.67(6.02)$ & $6.81(5.12)$ & $5.90(3.31)$ & $3.90(1.75)$ \\
\hline 1.00 & 4.00 & 5.00 & 4.0 & 18.9 (13.2) & $14.5(8.74)$ & $8.67(6.05)$ & $8.32(4.01)$ & $5.87(1.85)$ \\
\hline 1.00 & 1.00 & 1.00 & 4.0 & $2.81(2.87)$ & $2.06(2.42)$ & $1.86(2.05)$ & 1.95 (1.65) & $1.72(1.05)$ \\
\hline 1.00 & 1.00 & 3.00 & 4.0 & $5.56(5.05)$ & $4.25(3.92)$ & $3.07(3.49)$ & $2.80(2.41)$ & $2.37(1.29)$ \\
\hline 1.00 & 1.00 & 5.00 & 4.0 & $9.21(7.93)$ & $6.39(4.72)$ & $5.35(3.74)$ & $4.96(2.75)$ & 2.65 (1.59) \\
\hline 1.00 & 1.00 & 10.0 & 4.0 & $11.2(10.9)$ & $9.38(5.75)$ & $6.20(4.56)$ & $5.75(3.15)$ & $3.62(2.33)$ \\
\hline 1.00 & 1.00 & 15.0 & 4.0 & $13.4(13.0)$ & $12.3(6.89)$ & $7.98(4.92)$ & $7.42(3.55)$ & 4.19 (2.89) \\
\hline
\end{tabular}

Values in parentheses refer to the effect of [imidazole] and $\left[\mathrm{HClO}_{4}\right]$ in presence of $4.0 \times 10^{-4} \mathrm{~mol} \mathrm{dm}^{-3} \mathrm{BSA}$

Table 3 Effect of varying benzenesulfonamide concentration on the reaction rate at $303 \mathrm{~K}$

\begin{tabular}{llllll}
\hline$[\mathrm{BSA}] \times 10^{4} / \mathrm{mol} \mathrm{dm}^{-3}$ & \multicolumn{6}{l}{$k^{\prime} \times 10^{4} / \mathrm{s}^{-1}$} \\
\cline { 2 - 6 } & $2-$ & $2-$ & IzlH & $2-$ & $2-$ \\
& EtIzlH & MeIzlH & & EsIzlH & CaIzlH \\
\hline 0 & 9.21 & 6.39 & 5.35 & 4.96 & 2.65 \\
2.0 & 8.73 & 5.24 & 4.68 & 3.62 & 2.02 \\
4.0 & 7.93 & 4.72 & 3.74 & 2.75 & 1.59 \\
8.0 & 7.29 & 3.83 & 3.09 & 2.02 & 1.15 \\
\hline
\end{tabular}

$[\mathrm{CAB}]_{\mathrm{o}}=1.0 \times 10^{-4} \mathrm{~mol} \mathrm{dm}{ }^{-3}, \quad[\text { imidazole }]_{\mathrm{o}}=1.0 \times 10^{-3}$ $\mathrm{mol} \mathrm{dm}{ }^{-3},\left[\mathrm{HClO}_{4}\right]=5.0 \times 10^{-4} \mathrm{~mol} \mathrm{dm}{ }^{-3}$

benzenesulfonamide by varying concentrations of imidazole and $\mathrm{HClO}_{4}$ in the concentration range given in Table 2 .

From Eq. (17), plots of $1 / k^{\prime}$ vs. $1 /\left[\mathrm{H}^{+}\right]$at constant [imidazole $]$ and $\left[\mathrm{PhSO}_{2} \mathrm{NH}_{2}\right]$ were linear (Fig. 5; $\left.R^{2}>0.9900\right)$ with

Slope $=\frac{\left[\mathrm{PhSO}_{2} \mathrm{NH}_{2}\right]}{K_{1} K_{2} k_{3}[\text { Imidazole }]}$

and Intercept $=\frac{1}{K_{3} k_{3}[\text { Imidazole }]}+\frac{1}{k_{3}}$

From Eq. (18), plots of $1 / k^{\prime}$ vs. 1/[imidazole] at constant $\left[\mathrm{H}^{+}\right]$and $\left[\mathrm{PhSO}_{2} \mathrm{NH}_{2}\right]$ were linear (Fig. $6 ; R^{2}=0.9905$ ) with

Slope $=\frac{\left[\mathrm{PhSO}_{2} \mathrm{NH}_{2}\right]}{\mathrm{K}_{1} \mathrm{~K}_{2} \mathrm{k}_{3}\left[\mathrm{H}_{3} \mathrm{O}^{+}\right]}+\frac{1}{\mathrm{~K}_{2} \mathrm{k}_{3}}$ and Intercept $=\frac{1}{k_{3}}$
From the slopes and intercepts of the above plots, the values of equilibrium constants $K_{1}$ and $K_{2}$, and the decomposition constant $k_{3}$ were evaluated for all the imidazoles. These values are recorded in Table 6. The proposed mechanism and the derived rate law are supported by the experimental findings given below.

The proposed reaction mechanism is also evinced by the observed zero effect of ionic strength on the rate of the reaction. This can be justified by Brønsted and Bjerrum theory of salt effects [25]. According to this concept, the effect of ionic strength $(\mu)$ on the rate for a reaction involving two ions $\mathrm{A}$ and $\mathrm{B}$ is given by the relationship:

$\log k^{\prime}=\log k_{0}+1.018 \mathrm{Z}_{\mathrm{A}} \mathrm{Z}_{\mathrm{B}} \mu^{1 / 2}$

Here, $\mathrm{Z}_{\mathrm{A}}$ and $\mathrm{Z}_{\mathrm{B}}$ are the values of the ions $\mathrm{A}$ and $\mathrm{B}$, and $k^{\prime}$ and $k_{0}$ are the rate constants in the presence and in the absence of the added electrolyte, respectively. Above equation shows that a plot of $\log k^{\prime}$ vs. $\mu^{1 / 2}$ should be linear with a slope of $1.018 \mathrm{Z}_{\mathrm{A}} \mathrm{Z}_{\mathrm{B}}$ and an intercept of $\log k_{\mathrm{o}}$. As the slope of the line depends on $Z_{A} Z_{B}$, i.e., charges of the reacting ions, three special cases may rise: (a) if $A$ and $B$ have similar signs, then $\mathrm{Z}_{\mathrm{A}} \mathrm{Z}_{\mathrm{B}}$ will be positive and the rate constant $k^{\prime}$ increases with $\sqrt{ } \mu$; (b) if $\mathrm{A}$ and $\mathrm{B}$ have dissimilar charges, then $\mathrm{Z}_{\mathrm{A}} \mathrm{Z}_{\mathrm{B}}$ will be negative and the rate constant $k^{\prime}$ decreases with $\sqrt{ } \mu$; and (c) if either $\mathrm{A}$ or $\mathrm{B}$ is uncharged or neutral then $\mathrm{Z}_{\mathrm{A}} \mathrm{Z}_{\mathrm{B}}$ is equal to zero and $k^{\prime}$ is independent of the ionic strength of the solution. In the present case, variation of ionic strength of the medium does not alter the rate of reaction, this clearly signifies that one 
Table 4 Effect of varying dielectric constant of the medium on the reaction rate at $303 \mathrm{~K}$

\begin{tabular}{|c|c|c|c|c|c|c|}
\hline \multirow[t]{2}{*}{$\% \mathrm{MeOH}(\mathrm{v} / \mathrm{v})$} & \multirow[t]{2}{*}{$D$} & \multicolumn{5}{|c|}{$k^{\prime} \times 10^{4} / \mathrm{s}^{-1}$} \\
\hline & & 2-EtIzlH & 2-MeIzlH & IzlH & 2-EsIzlH & 2-CaIzlH \\
\hline 0 & 76.73 & 9.21 & 6.39 & 5.35 & 4.96 & 2.65 \\
\hline 5 & 74.50 & 13.1 & 9.31 & 8.42 & 6.29 & 3.40 \\
\hline 10 & 72.37 & 18.2 & 12.9 & 11.1 & 9.24 & 5.36 \\
\hline 15 & 69.75 & 25.8 & 18.4 & 16.4 & 12.8 & 7.22 \\
\hline
\end{tabular}

$[\mathrm{CAB}]_{\mathrm{o}}=1.0 \times 10^{-4} \mathrm{~mol} \mathrm{dm}^{-3},[\text { imidazole }]_{\mathrm{o}}=1.0 \times 10^{-3} \mathrm{~mol} \mathrm{dm}^{-3},\left[\mathrm{HClO}_{4}\right]=5.0 \times 10^{-4} \mathrm{~mol} \mathrm{dm}^{-3}$

Table 5 Effect of varying temperature on the reaction rate and activation parameters for the oxidation of imidazoles by CAB in acid medium

\begin{tabular}{|c|c|c|c|c|c|}
\hline \multirow[t]{2}{*}{ Temperature/K } & \multicolumn{5}{|c|}{$k^{\prime} \times 10^{4} / \mathrm{s}^{-1}$} \\
\hline & 2-EtIzlH & 2-MeIzlH & $\mathrm{IzlH}$ & 2-EsIzlH & 2-CaIzlH \\
\hline 288 & 3.09 & 2.32 & 1.89 & 1.75 & 1.01 \\
\hline 293 & 4.60 & 3.19 & 2.57 & 2.48 & 1.31 \\
\hline 298 & 6.34 & 4.68 & 3.87 & 3.58 & 1.89 \\
\hline 303 & 9.21 & 6.39 & 5.35 & 4.96 & 2.65 \\
\hline 308 & 13.5 & 9.69 & 7.92 & 6.95 & 3.80 \\
\hline 313 & 18.5 & 13.2 & 11.0 & 10.1 & 5.32 \\
\hline 318 & 26.5 & 18.9 & 15.7 & 14.2 & 7.94 \\
\hline 323 & 34.5 & 25.8 & 21.9 & 21.4 & 10.5 \\
\hline$E_{\mathrm{a}} / \mathrm{kJ} \mathrm{mol}^{-1}$ & 49.8 & 52.6 & 54.7 & 57.6 & 64.3 \\
\hline$\Delta H^{\neq} / \mathrm{kJ} \mathrm{mol}^{-1}$ & 48.0 & 50.1 & 52.2 & 55.1 & 58.2 \\
\hline$\Delta G^{\neq} / \mathrm{kJ} \mathrm{mol}^{-1}$ & 89.6 & 92.9 & 93.5 & 93.7 & 95.1 \\
\hline$\Delta S^{\neq} / \mathrm{J} \mathrm{K}^{-1} \mathrm{~mol}^{-1}$ & -140 & -135 & -131 & -126 & -120 \\
\hline $\log A$ & 10.0 & 9.77 & 9.61 & 10.0 & 10.3 \\
\hline
\end{tabular}

$[\mathrm{CAB}]_{\mathrm{o}}=1.0 \times 10^{-4} \mathrm{~mol} \mathrm{dm}^{-3},[\text { imidazole }]_{\mathrm{o}}=1.0 \times 10^{-3} \mathrm{~mol} \mathrm{dm}^{-3},\left[\mathrm{HClO}_{4}\right]=5.0 \times 10^{-4} \mathrm{~mol} \mathrm{dm}^{-3}$

\section{Scheme 2}

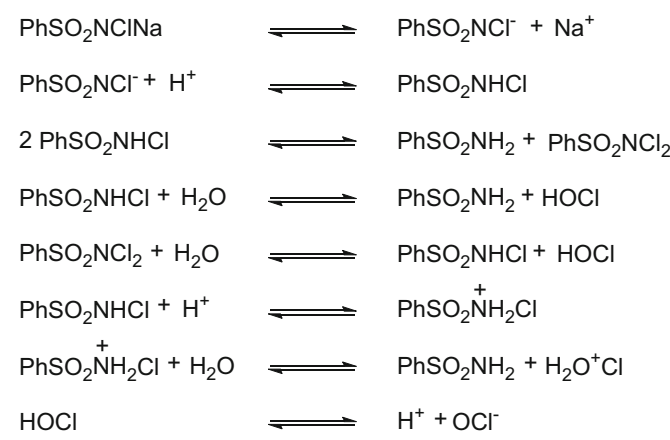

of the reactant species is a neutral molecule as seen in slow/rls of Scheme 4. Hence, the observed ionic strength effect is in agreement with the above theory.

The effect of changing solvent composition on the rate of reaction has been described in detail in various

(2)

(9)

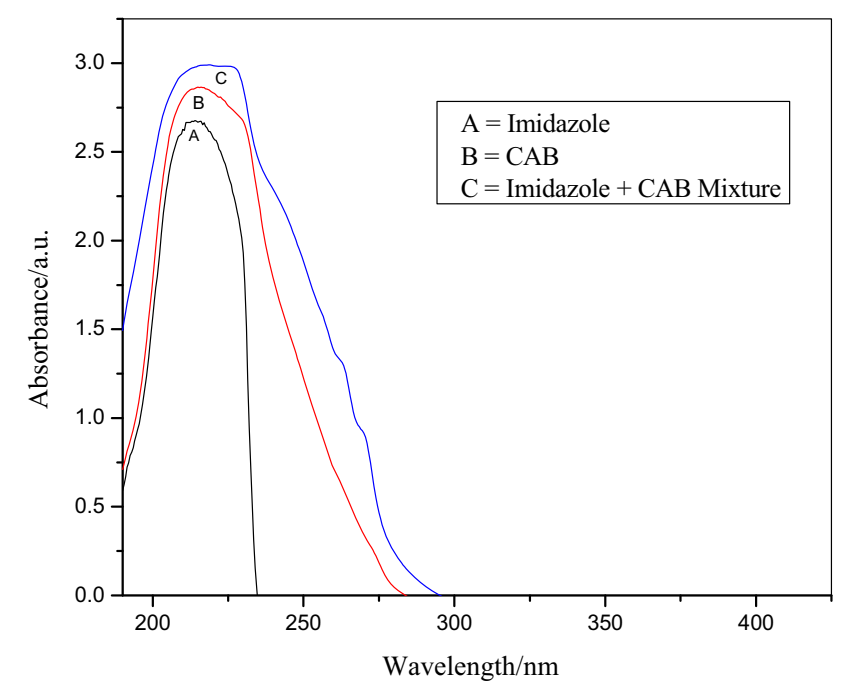

Fig. 4 UV-Vis spectra of (A) imidazole, (B) CAB, and (C) a mixture of both in an acid medium 
monographs [26-30]. The dependence of the rate constant on the dielectric constant of the medium is given by the following relationship:

\section{Scheme 3}

$$
\begin{array}{ll}
\mathrm{PhSO}_{2} \mathrm{NHCl}+\mathrm{H}_{3} \mathrm{O}^{+} \stackrel{K_{1}}{\rightleftharpoons} \mathrm{PhSO}_{2} \mathrm{NH}_{2}+\mathrm{H}_{2} \mathrm{O}^{+} \mathrm{Cl} \\
\mathrm{H}_{2} \mathrm{O}^{+} \mathrm{Cl}+\text { Imidazole } & \stackrel{K_{2}}{\rightleftharpoons} \text { Complex } \\
\text { Complex } & \stackrel{k_{3}}{\longrightarrow} \text { Products }
\end{array}
$$
(i) fast
(ii) fast
(iii) slow \& rls

$\ln k^{\prime}=\ln k_{0}^{\prime}\left(\frac{N Z_{\mathrm{A}} \mathrm{Z}_{\mathrm{B}} \mathrm{e}^{2}}{D R T r_{\#}}\right)$

In this equation, $k_{o}{ }^{\prime}$ is the rate constant in a medium of infinite dielectric constant, $Z_{\mathrm{A}} \mathrm{e}$ and $\mathrm{Z}_{\mathrm{B}} \mathrm{e}$ are the total charges on the ions $\mathrm{A}$ and $\mathrm{B}, r_{\#}$ is the radius of the activated complex, $R, T$, and $N$ have their usual meanings. The equation predicts a linear plot of $\log k^{\prime}$ vs. $1 / D$ with a negative slope if the charges on the ions are of the same sign and a positive slope if they are opposite sign. The positive dielectric effect observed in the present study (Table 4) clearly supports the involvement of dissimilar charges in the rate-limiting step (Scheme 4).

Scheme 4

(i)

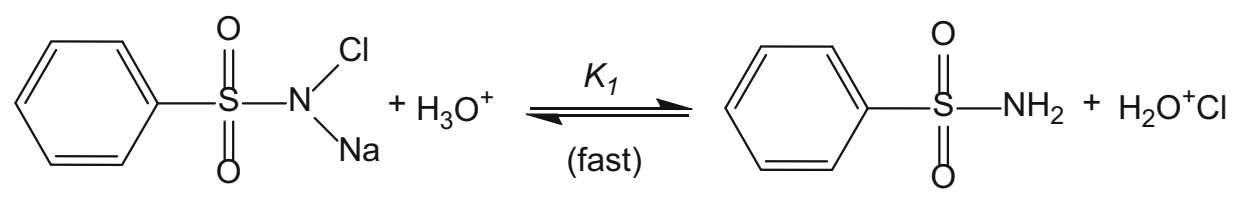

Chloramine-B

Benzenesulfonamide

(ii)

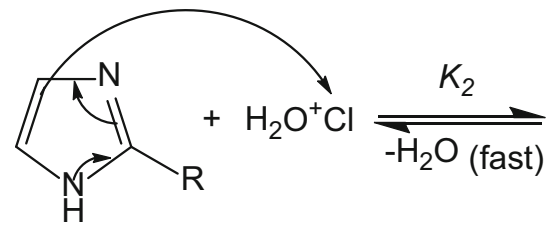

Imidazole

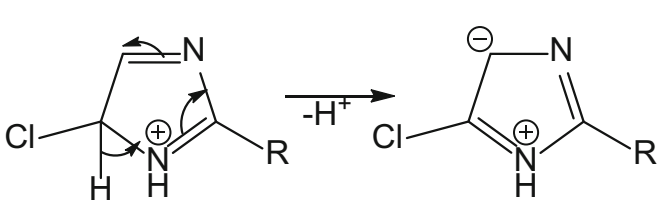<smiles>[R]C1=N[C@H](C)C(Cl)=N1</smiles>

Intermediate

(iii)<smiles>[R]C1=NC[C@](Cl)(CO)[NH2+]1</smiles>

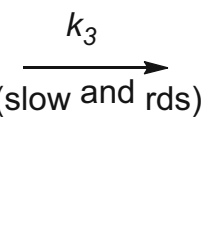<smiles>[OH2+]C1(Cl)CN=C(F)N1</smiles><smiles>[R][CH-]C</smiles><smiles>[R]C1=NCC2(CC)NC(OC1)[C@@H]2C</smiles><smiles>[R]C1=N[C@H](C(=O)O[Na])C(=O)N1</smiles> 


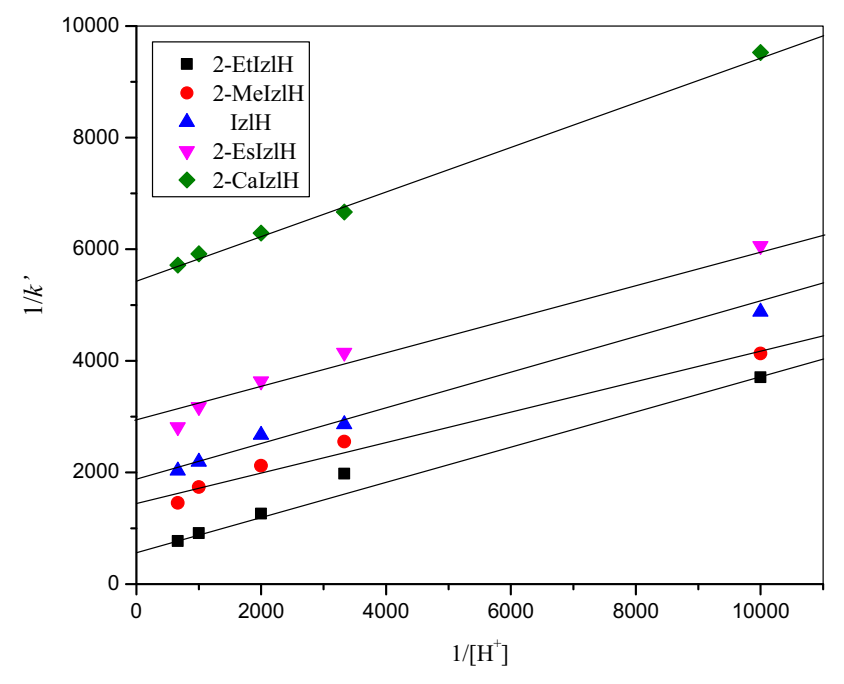

Fig. 5 Plots of $\log 1 / k^{\text {'vs. }} 1 /\left[\mathrm{H}^{+}\right]$at constant [BSA]

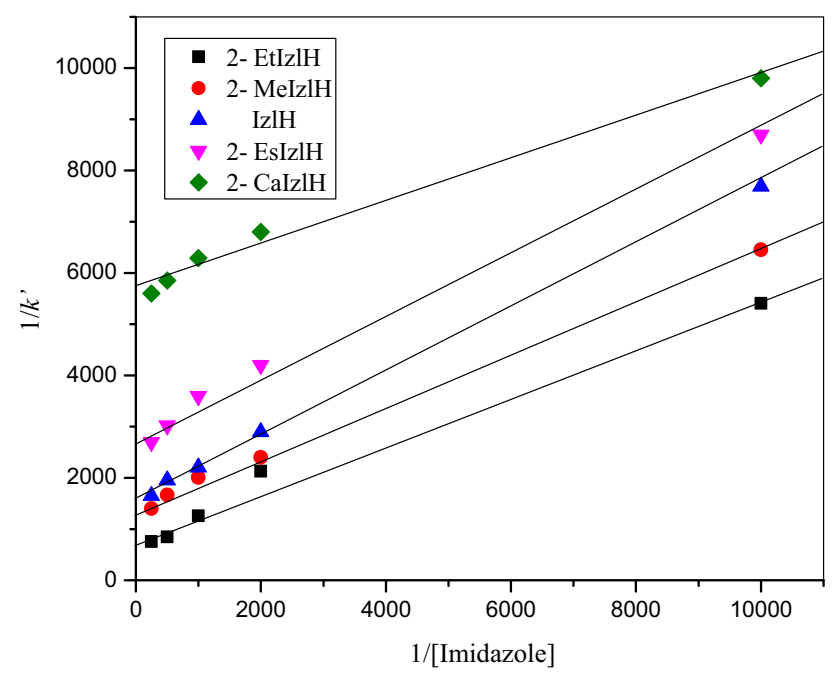

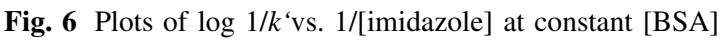

Table 6 Values of equilibrium and decomposition constants

\begin{tabular}{lccc}
\hline Substrate & $K_{1} \times 10^{2}$ & $\begin{array}{l}K_{2} \times 10^{3} \\
/ \mathrm{dm}^{-3} \mathrm{~mol}^{-1}\end{array}$ & $\begin{array}{l}k_{3} \times 10^{4} \\
/ \mathrm{s}^{-1}\end{array}$ \\
\hline 2-EtIzlH & 25.0 & 2.66 & 12.5 \\
2-MeIzlH & 14.5 & 6.50 & 7.70 \\
IzlH & 14.8 & 3.50 & 7.14 \\
2-EsIzlH & 50.8 & 25.0 & 3.84 \\
2-CaIzlH & 41.7 & 14.2 & 1.69 \\
\hline
\end{tabular}

It can be seen from the Table 5 that the rate of oxidation of imidazoles by $\mathrm{CAB}$ in presence of $\mathrm{HClO}_{4}$ increases in the order: 2-EtIzlH $>2$-MeIzlH $>$ IzlH $>2$-EsIzlH $>2$ CaIzlH. This trend due to combined effect of the electronic and steric factors of the substitutents attached to the 2position of imidazole ring. The higher reactivity of
2-EtIzlH in comparison with 2-MeIzlH can be endorsed due to the differences in the electron donating effect of the $-\mathrm{C}_{2} \mathrm{H}_{5}$ and $-\mathrm{CH}_{3}$ groups and also through the positive inductive effect, thereby enhancing the electron density by imidazolium ring make the reaction very fast. Furthermore, 2-CaIzlH have least reactive assessment with 2-EsIzlH because the attached electron withdrawing group in 2-CaIzlH rapidly decreases the nucleophilicity on the aromatic ring than electron withdrawing group present in 2-EsIzlH.

\section{Isokinetic relationship}

The rate constants and activation energies in Table 5 reveal that activation energy is highest for the slowest reaction and vice versa as expected indicating that the reaction is under enthalpy control. This is verified by calculating the isokinetic temperature $(\beta)$ from the slope of the linear plot of $\Delta H^{\neq}$vs. $\Delta S^{\neq}$(Fig. 7; $R^{2}=0.9987$ ). The value $\beta$ found is $453 \mathrm{~K}$, which is higher than the experimental temperature $(303 \mathrm{~K})$ employed in the present work. The genuine nature of isokinetic relationship was also tested through the Exner criterion [31] by plotting $\log k_{(303 \mathrm{~K})}^{\prime}$ vs. $\log k_{(293 \mathrm{~K})}^{\prime}$ (Fig. $7 ; R^{2}=0.9993$ ). The isokinetic temperature $\beta$ can be evaluated from the expression: $\quad \beta=T_{1} T_{2}(q-1) /$ $\left(q T_{2}-T_{1}\right)$ where $q$ is the slope of the Exner plot; $\beta$ was found to be $449 \mathrm{~K}$. The proposed mechanism is also supported by the moderate values of energy of activation and other activation parameters. The fairly high negative $\Delta S^{f}$ values reflect a greater degree of ordering in the transition state than the initial state, due to an increase in solvation during the solvation process. The near constancy of $\Delta G^{\neq}$ values indicates that the same types of reaction mechanism could be operative for all the five imidazoles studied.

\section{Conclusion}

In the course of this research, optimum conditions for the facile oxidative conversion of imidazole (IzlH) and 2substituited imidazoles viz., 2-ethyl-1H-imidazole (2-EtIzlH), 2-methyl-1 $H$-imidazole (2-MeIzlH), $1 H$-imidazole-2ester (2-EsIzlH), and $1 \mathrm{H}$-imidazole-2-carbaldehyde (2$\mathrm{CaIzlH})$ to the corresponding imidazolones with chloramine-B have been developed in acid medium. These reactions follow identical kinetics with a rate law:

$-\mathrm{d}[\mathrm{CAB}] / \mathrm{d} t=k[\mathrm{CAB}]_{o}[\text { imidazole }]_{o}^{x}\left[\mathrm{H}^{+}\right]^{y}[\mathrm{BSA}]^{-z}$

where $x, y$, and $z<1$; BSA is benzenesulfonamide. Activation parameters and reaction constants have been deduced. The isokinetic temperature was evaluated. The rate of oxidation of imidazoles follows the order: 2-EtIzlH $>$ 2-MeIzlH $>$ IzlH $>2$-EsIzlH $>2$-CaIzlH. A 
Fig. 7 Isokinetic plots of (a) $\log k^{\prime \prime}{ }_{(303 \mathrm{~K})}$ vs. $\log k^{\prime \prime}{ }_{(293 \mathrm{~K})}$ (b) $\Delta H^{\neq}$vs. $\Delta S^{\neq}$

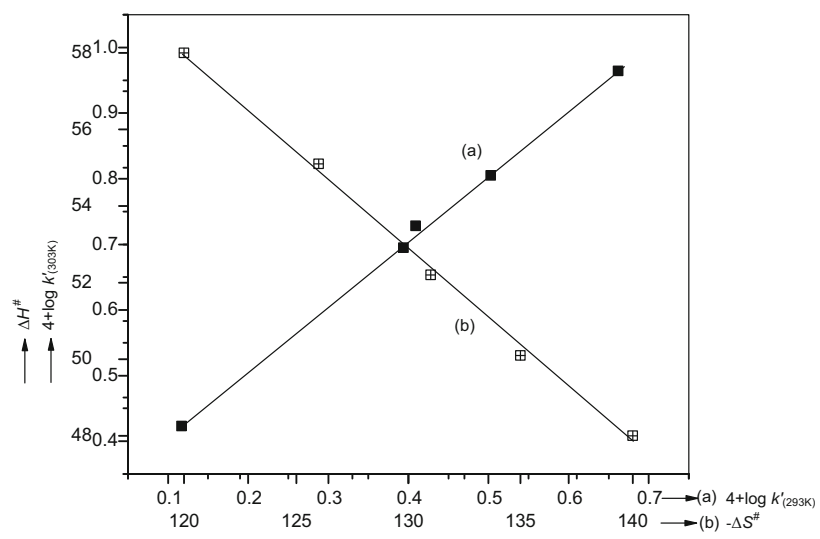

suitable reaction scheme is proposed and an appropriate rate law is deduced to account for the observed experimental results. The present method offers many advantages including high yield, simplicity, short reaction times, costeffectivity and involvement of non-toxic reagents which make the reaction process is simple, smooth, and environmentally benign. Hence, this redox system can be scaled up to industrial process with suitable modification.

\section{Experimental}

Sigma make chloramine-B was purified by the method of Morris et al. [20]. An aqueous solution of CAB was prepared and standardized by iodometric method. 2-Ethyl- $1 \mathrm{H}$-imidazole and $1 H$-imidazole-2-carbaldehyde (Sigma), 2-methyl-1H-imidazole (SRL Pvt. Ltd., India), $1 H$-imidazole (SD Fine Chem. Ltd., India) and $1 H$-imidazole-2-ester (Avra Synthesis Pvt. Ltd., India) were of acceptable grades of purity and were used as received. Aqueous solutions of the compounds were used for kinetic studies. Reagent grade chemicals and doubly distilled water were used throughout the experiment. SL 159 Elico UV-Vis spectrophotometer was used for studying the formation of intermediate complex. GC-MS data were obtained on a 17A Shimadzu gas chromatograph with a QP-5050A Shimadzu mass spectrometer. NMR spectra were obtained on a Bruker WH 400-MHz nuclear magnetic resonance spectrometer.

\section{Kinetic measurements}

The kinetic runs were performed under pseudo-first-order conditions with a known excess of [substrate] over [oxidant] in acid medium at $303 \mathrm{~K}$. The progress of the reaction was monitored by the iodometric method. The experimental procedure we followed here was identical to that reported earlier [15]. The course of the reaction was studied for at least two half-lives. The pseudo-first-order rate constants $\left(k^{\prime} / \mathrm{s}^{-1}\right)$ calculated from the linear plots of $\log$ $[C A B]$ vs. time. All the kinetic runs were carried out twice to check the reproducibility. The values are found to be reproducible within $\pm 3-6 \%$ error. Regression coefficient $\left(R^{2}\right)$ were calculated using $f x-100 \mathrm{~W}$ scientific calculator.

Acknowledgments The authors are thankful to Prof. M. A. Pasha of this Department for his valuable suggestions on the proposed reaction scheme.

\section{References}

1. Hendrickson JB, Cram DJ, Hammond GS (1970) Organic Chemistry, 3rd edn. Mc-Graw Hill Book Co, New York

2. Laidler KJ (1995) Chemical Kinetics, 2nd edn. Tata Mc-Graw Hill, New Delhi

3. Hoffmann K (1953) Imidazole and its Derivatives. Interscience, New York

4. Bhatnagar A, Sharma PK, Kumar N (2011) Int J Pharm Tech Res 3:268

5. Haneda S, Okui A, Ueba C, Hayashi M (2007) Tetrahedron 63:2414

6. Alnashet IM, Hashim MA, Mjalli FS, Al-Haj Ali MA, Hayyan M (2010) Tetrahedron Lett 51:1976

7. Campbell MM, Johnson G (1978) Chem Rev 78:65

8. Banerji KK, Jayaram B, Mahadevappa DS (1987) J Sci Ind Res 46:65

9. Agarwal M, Upadhyay SK (1990) J Sci Ind Res 49:13

10. Armexo XL, Canle L, Garcia MV, Santaballa JA (1998) Chem Soc Rev 27:453

11. Agnihotri G (2005) Synlett 2857 
12. Kolaveri E, Ghorbeni-Choghamarani A (2007) J Iran Chem Soc $2: 126$

13. Jagadeesh RV, Puttaswamy (2013) Chloramine-T. In: Electronic Encyclopedia of reagents for organic synthesis. John Wiley \& Sons Ltd., http://onlinelibrary.wiley.com/book/10.1002/ 047084289X

14. Rangappa KS, Raghavendra MP, Mahadevappa DS (1997) J Carbohydr Chem 16:359

15. Puttaswamy, Jagadeesh RV (2005) Cent Eur J Chem 3:482

16. Puttaswamy, Shubha JP, Jagadeesh RV (2007) Trans Met Chem 32:991

17. Akerloff G (1932) J Am Chem Soc 54:4125

18. Murthy ARV, Rao BS (1952) Proc Ind Acad Sci 35:69

19. Bishop E, Jennings VJ (1958) Talanta 1:197

20. Morris JC, Salazar JA, Wineman MA (1948) J Am Chem Soc 70:2036

21. Hardy FF, Johnston JP (1973) J Chem Soc Perkin Trans 2:742
22. Soper FG (1924) J Chem Trans 125:1899

23. Swain CG, Crist DR (1972) J Am Chem Soc 94:3195

24. Gowda BT, Mahadevappa DS (1983) J Chem Soc Perkin Trans $2: 323$

25. Maron SH, Prutton CF (1972) Principles of Physical Chemistry. Macmillon Co, New York

26. Amis ES, Jaffe G (1942) J Chem Phys 10:598

27. Kirkwood JG (1934) J Chem Phys 2:351

28. Laidler KJ, Landskroener PA (1957) Trans Faraday Soc 52:200

29. Entelis SG, Tiger RP (1976) Reaction Kinetics in the Liquid Phase. Wiley, New York

30. Amis ES (1966) Solvent Effects on Reaction Rates and Mechanism. Academic Press, New York

31. Exner O (1964) Collect Czech Chem Commun 29:1094 